\title{
Beta-blockers and health-related quality of life in patients with peripheral arterial disease and COPD
}

This article was published in the following Dove Press journal:

International Journal of COPD

6 May 2009

Number of times this article has been viewed

\section{Yvette RBM van Gestel' \\ Sanne E Hoeks' \\ Don D $\operatorname{Sin}^{2}$ \\ Henk Stam ${ }^{3}$ \\ Frans W Mertens ${ }^{3}$ \\ Jeroen J Bax ${ }^{4}$ \\ Ron T van Domburg ${ }^{5}$ \\ Don Poldermans ${ }^{6}$}

'Department of Anesthesiology, Erasmus Medical Center, Rotterdam, The Netherlands; ${ }^{2}$ Department of Medicine, University of British Columbia and The James Hogg iCAPTURE Center, St. Paul's Hospital, Vancouver, Canada; ${ }^{3}$ Department of Pulmonology, Erasmus Medical Center, Rotterdam, The Netherlands; ${ }^{4}$ Department of Cardiology, Leiden University Medical Center, Leiden,

The Netherlands; ${ }^{5}$ Department of Cardiology, Erasmus Medical Center, Rotterdam, The Netherlands; ${ }^{6}$ Department of Vascular Surgery, Erasmus Medical Center, Rotterdam, The Netherlands
Correspondence: Don Poldermans Erasmus Medical Center Rotterdam, 's-Gravendijkwal 230, 30I5 CE Rotterdam Tel +3I I0 70346I3

Fax + 3I 107034957

Email d.poldermans@erasmusmc.nl
Background: Beta-blockers are frequently withheld in patients with cardiovascular disease who also have chronic obstructive pulmonary disease (COPD) because of concerns that they might provoke bronchospasm and cause deterioration in health status. Although beta1-selective beta-blockers are associated with reduced mortality in COPD patients, their effects on health status are unknown. The aim of this study was to investigate the relationship between betablockers and health-related quality of life (HRQOL) in patients with peripheral arterial disease and COPD.

Methods: Of the original cohort of 3371 vascular surgery patients, 1310 had COPD of whom 469 survived during long-term follow-up. These COPD patients were sent the Short Form-36 (SF-36) health-related quality of life questionnaire, which was completed and returned by $326(70 \%)$ patients.

Results: No significant differences in any of the SF-36 domains were observed between COPD patients who did and did not use beta-blockers ( $p>0.05$ for all). Furthermore, beta-blockers were not associated with any impairment in HRQOL among patients with COPD.

Conclusion: Beta-blockers had no material impact on the HRQOL of patients with peripheral arterial disease who also had COPD. This suggests that beta-blockers can, in most circumstances, be administered to patients with COPD without impairment in HRQOL.

Keywords: beta-blockers, chronic obstructive pulmonary disease, vascular surgery, healthrelated quality of life

\section{Introduction}

Patients with chronic obstructive pulmonary disease (COPD) often have or develop co-existing cardiovascular diseases including congestive heart failure, ischemic heart disease and hypertension. ${ }^{1}$ Beta-blockers are indicated in most of these conditions, as they improve heart function, symptoms and survival. ${ }^{2,3}$ However, there is underutilization of beta-blockers in cardiovascular patients with COPD because of concerns that these drugs may induce bronchoconstriction and worsen symptoms. ${ }^{4}$ Although the data are mixed, the total evidence suggests that betal-selective beta-blockers (at least in the short term) do not worsen pulmonary function ${ }^{5-10}$ and are associated with reduced mortality in patients with cardiovascular disease who have COPD. ${ }^{11-13}$ The long-term effects on health status and health-related quality of life (HRQOL) of beta-blockers in COPD are unknown. On the one hand, beta-blockers may improve HRQOL because of their beneficial effects on cardiac performance; on the other hand, beta-blockers may cause impaired physical, social and emotional functioning owing to their side effects and/or by causing worsening of lung function. The latter may partly explain 
the sub-optimal prescription rate of these drugs for patients with COPD. We thus sought to determine the relationship between beta-blockers and HRQOL of patients with peripheral arterial disease, who also had COPD.

\section{Methods}

\section{Patients}

The study is based on a subgroup of the original cohort of vascular surgery patients, who have been described previously. ${ }^{13}$ Briefly, a detailed cardiac history, in addition to clinical and demographic characteristics, were obtained in all patients undergoing a peripheral vascular operative procedure prior to their surgery. Their survival status was ascertained at long-term follow-up (up to 10 years) using the municipal civil registry. HRQOL of patients was determined at followup using a self-administered questionnaire that was mailed to all eligible subjects (see below). In this mailing, we also obtained information regarding the use of beta-blockers using a short questionnaire.

\section{COPD}

The diagnosis of COPD was based on spirometric evidence for fixed airflow obstruction as assessed by a post-bronchodilator forced expiratory volume in one second $\left(\mathrm{FEV}_{1}\right)$ to forced vital capacity (FVC) ratio of less than 0.70 and $\mathrm{FEV}_{1}$ of $<80 \%$ of predicted, which was obtained at baseline prior to their original vascular surgery. ${ }^{14}$ Patients who did not undergo spirometry were categorized as not having COPD if they did not complain of cough, dyspnea or sputum production, were not taking any pulmonary medication (bronchodilators or corticosteroids) and demonstrated normal arterial blood gases on room air defined by arterial carbon dioxide tension $\left(\mathrm{paCO}_{2}\right)<6.4 \mathrm{kPa}$ and oxygen tension $\left(\mathrm{paO}_{2}\right)>10.0 \mathrm{kPa}$. Patients without spirometry who met any one of these criteria were classified as having COPD.

\section{Health-related quality of life}

For the assessment of HRQOL, the Dutch version of the Medical Outcomes Study 36-Item Short Form Health Survey (SF-36) was used. ${ }^{15,16}$ SF-36 is a widely used generic questionnaire to measure patients' health status and has been used previously in patients with COPD. ${ }^{17-19}$ The questionnaire contains 36 items covering 8 domains: physical functioning $(\mathrm{PF})$, role physical (RP), bodily pain (BP), general health $(\mathrm{GH})$, vitality (VT), social functioning (SF), role emotional (RE) and mental health $(\mathrm{MH})$. The domains scores range from 0 to 100 , with higher scores indicating better HRQOL.

\section{Statistical analysis}

The primary exposure variable was the use of beta-blockers at baseline and the primary endpoint of the present study was HRQOL at follow-up. The baseline categorical variables of the patients who did and did not use a beta-blocker were compared using a chi-square test for dichotomous variables and a Student's t-test for continuous variables. Dichotomous variables are presented as percentages, while continuous variables are presented as mean \pm standard deviation (SD). The domains of the SF-36 were converted into tertiles for parsimony and subsequently dichotomized, ${ }^{20,21}$ with the lowest tertile indicating worst health status and the highest two tertiles representing best health status. Univariate and multivariate logistic regression analyses were used to determine the association between beta-blocker use and health status. In the multivariate analysis, adjustments were made for all baseline characteristics that might reasonably affect HRQOL including age, gender, diabetes mellitus, hypertension, hypercholesterolemia, renal dysfunction, current smoking, obesity, type of surgery (abdominal aortic surgery [AAA], carotid endarterectomy [CEA], or lower limb arterial reconstruction procedures [LLR]), year of surgery, previous ischemic heart disease (myocardial infarction, coronary artery bypass graft, percutaneous coronary intervention or angina pectoris), heart failure, cerebrovascular event (CVA) or transient ischemic attack (TIA), statins, aspirin, corticosteroids and bronchodilators. To correct for the differential follow-up, adjustments were made for the number of follow-up years. Additionally, a propensity score was added as a covariate to the model to adjust for the likelihood of receiving betablockers. This propensity model contained all variables which were included in the logistic regression analysis, except for the number of follow-up years. Odds ratios (OR) are presented as risk estimates with $95 \%$ confidence intervals (CI). For all tests, a 2 -sided p-value of $<0.05$ was considered significant. All tests were performed using SPSS 15.0 for Windows.

\section{Results}

\section{Patients}

In total, 1310 (39\%) of the original 3371 patients had COPD. Of these patients, two had moved abroad, 28 were lost to follow-up and 469 (36\%) survived during the follow-up period. The median follow-up time was 6.4 years with an interquartile range of 2.9 to 9.3 years. All 469 patients were sent the SF-36 questionnaire at follow-up, which was completed and returned by 326 (70\%) patients. An overview of the patient inclusion for this study is presented in Figure 1. 


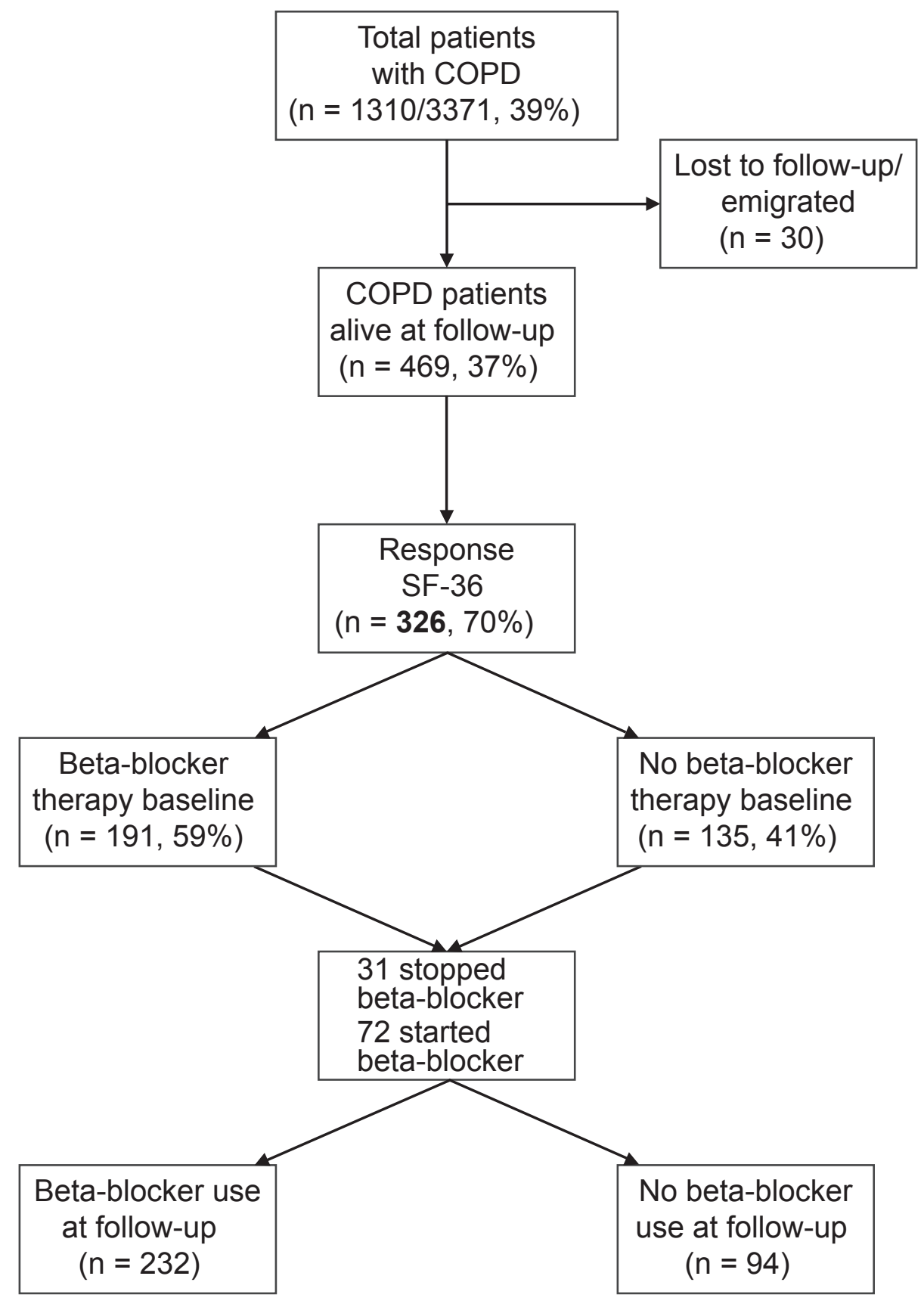

Figure I Patient flow chart.

Clinical baseline characteristics are presented in Table 1. Of the 326 patients with peripheral arterial disease and COPD, $59 \%(\mathrm{n}=191)$ received beta-blockers. The mean age was $66 \pm 10$ years and $80 \%(n=262)$ were men. Patients on beta-blockers were older and were more likely to have had a previous myocardial infarction, coronary revascularization, angina pectoris, diabetes mellitus, renal dysfunction and hypercholesterolemia compared with those who were not on beta-blockers (all p-values $<0.05$ ). These patients also received more often other medications like statins, aspirin and corticosteroids $(\mathrm{p}<0.05)$. Only two differences were found in baseline characteristics between the COPD patients who filled out the questionnaire and those who did not respond. The non-responding patients were more likely to be women and had more frequent history of renal dysfunction $(\mathrm{p}<0.05)$.

\section{Beta-blockers and COPD}

Of the 326 responding COPD patients, 191 (59\%) patients used beta-blockers at baseline. Of these, 174 (91\%) received 
Table I Baseline characteristics of the study patients

\begin{tabular}{|c|c|c|c|c|}
\hline & $\begin{array}{l}\text { Total } \\
(n=326)\end{array}$ & $\begin{array}{l}\text { Beta-blockers }^{a} \\
(n=191)\end{array}$ & $\begin{array}{l}\text { No beta-blockers } \\
(n=135)\end{array}$ & $\overline{\text { p-value }}$ \\
\hline \multicolumn{5}{|l|}{ Demographics } \\
\hline Mean age years (mean (SD)) & $66(10)$ & $68(9)$ & $64(11)$ & $<0.001$ \\
\hline Male gender & $80 \%$ & $81 \%$ & $79 \%$ & 0.67 \\
\hline Type of surgery & & & & 0.28 \\
\hline AAA & $50 \%$ & $53 \%$ & $44 \%$ & \\
\hline CEA & $21 \%$ & $20 \%$ & $23 \%$ & \\
\hline LLR & $29 \%$ & $27 \%$ & $33 \%$ & \\
\hline \multicolumn{5}{|l|}{ Cardiovascular history } \\
\hline Myocardial infarction & $26 \%$ & $33 \%$ & $16 \%$ & $<0.01$ \\
\hline Coronary revascularization ${ }^{\mathrm{b}}$ & $23 \%$ & $28 \%$ & $15 \%$ & $<0.01$ \\
\hline Heart failure & $5 \%$ & $4 \%$ & $5 \%$ & 0.67 \\
\hline Angina pectoris & $20 \%$ & $29 \%$ & $8 \%$ & $<0.001$ \\
\hline Stroke or TIA & $25 \%$ & $25 \%$ & $25 \%$ & 0.91 \\
\hline \multicolumn{5}{|l|}{ Clinical characteristics } \\
\hline COPD & & & & 0.43 \\
\hline Mild COPD & $54 \%$ & $54 \%$ & $53 \%$ & \\
\hline Moderate COPD & $37 \%$ & $36 \%$ & $40 \%$ & \\
\hline Severe COPD & $9 \%$ & $11 \%$ & $7 \%$ & \\
\hline Hypertension & $43 \%$ & $46 \%$ & $39 \%$ & 0.26 \\
\hline Diabetes mellitus & $14 \%$ & $20 \%$ & $4 \%$ & $<0.001$ \\
\hline Hypercholesterolemia & $23 \%$ & $28 \%$ & $16 \%$ & $<0.0$ I \\
\hline Renal dysfunction & $19 \%$ & $23 \%$ & $12 \%$ & 0.01 \\
\hline Body mass index (mean (SD)) & $26(4)$ & $26(4)$ & $26(4)$ & 0.81 \\
\hline Current smoking status & $31 \%$ & $32 \%$ & $29 \%$ & 0.56 \\
\hline \multicolumn{5}{|l|}{ Medication } \\
\hline Statins & $44 \%$ & $58 \%$ & $23 \%$ & $<0.001$ \\
\hline Aspirin & $49 \%$ & $56 \%$ & $39 \%$ & $<0.01$ \\
\hline Bronchodilators & $10 \%$ & $11 \%$ & $10 \%$ & 0.98 \\
\hline Corticosteroids & $15 \%$ & $19 \%$ & $10 \%$ & 0.04 \\
\hline
\end{tabular}

a Use at baseline.

${ }^{b}$ Coronary artery bypass graft (CABG) or percutaneous coronary intervention $(\mathrm{PCI})$.

Abbreviations: AAA, abdominal aortic surgery; CEA, carotid endarterectomy; LLR, lower limb arterial reconstruction; TIA, transient ischemic attack; COPD, chronic obstructive pulmonary disease.

a beta1-selective beta-blocker (ie, bisoprolol, metoprolol or atenolol). Of the 191 patients who had received beta-blockers at baseline, $31(16 \%)$ had discontinued its use (by self-report) at follow-up. All of these patients were probed to ascertain the cause for the discontinuation; in no case was worsening of pulmonary symptoms noted. The distribution of beta-blocker discontinuation between those with and without COPD was similar (of the patients who had discontinued, 54\% did not have COPD and 46\% had COPD). At baseline 135 COPD patients were not treated with beta-blockers, however at follow-up, $72(53 \%)$ of these patients had initiated beta-blocker therapy. In total, $232(71 \%)$ patients were using beta-blockers by the end of follow-up. Of these, 204 (88\%) used beta1-selective beta-blockers (Figure 1).

\section{Health-related quality of life}

The mean scores on the SF-36 domains according to beta-blocker use are presented in Figure 2a. There were no significant differences in HRQOL scores between those who were and were not taking beta-blockers ( $\mathrm{p}>0.05$ for all). Multivariate analyses also showed no significant associations between betablockers and the individual domains of the SF-36 in patients with COPD: (PF: OR 1.36; 95\% CI 0.72-2.61, RP: OR 1.55; 95\% CI 0.78-3.06, BP: OR 1.00; 95\% CI 0.52-1.94, GH: OR 1.27; 95\% CI 0.67-2.41, VT: OR 1.29; 95\% CI 0.68-2.44, 
A

Beta-blocker therapy at baseline No beta-blocker therapy at baseline

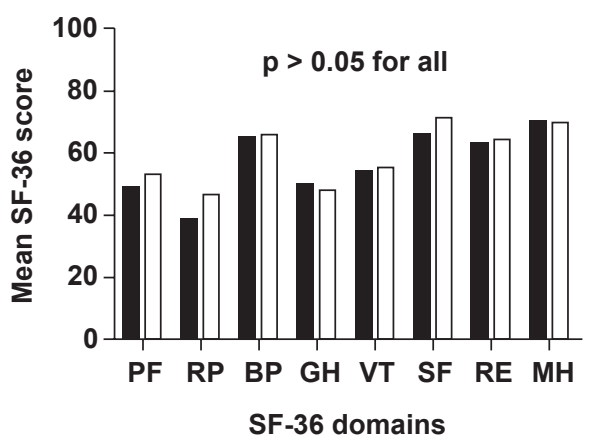

B Beta-blocker therapy at follow-up
$\square$ No beta-blocker therapy at follow-up

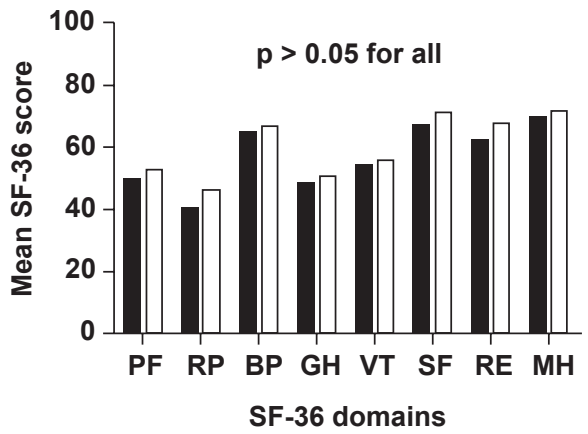

Figure 2 Mean SF-36 scores. A) Mean SF-36 scores of COPD patients with betablocker therapy at baseline; B) Mean SF-36 scores of COPD patients with beta-blocker therapy at follow-up.

Abbreviations: PF, physical functioning; RP, role physical; BP, bodily pain; $\mathrm{GH}$, general health; VT, vitality; SF, social functioning; RE, role emotional; $\mathrm{MH}$, mental health.

SF: OR 1.59; 95\% CI 0.87-2.92, RE: OR 1.00; 95\% CI 0.50-1.97, MH: OR 1.15; 95\% CI 0.62-2.14) (Figure 3a).

We also evaluated the impact of beta-blocker use at follow-up on HRQOL. Again, there were no significant differences in mean HRQOL scores between patients who were and were not treated with beta-blockers (Figure $2 \mathrm{~b}$ ). Beta-blocker therapy at follow-up was not associated with impaired health status (PF: OR 1.27; 95\% CI 0.72-2.27, RP: OR 1.66; 95\% CI 0.92-2.98, BP: OR 0.96; 95\% CI 0.55-1.69, GH: OR $1.50 ; 95 \%$ CI $0.84-2.66$, VT: OR $1.22 ; 95 \%$ CI 0.69-2.14, SF: OR 1.34; 95\% CI 0.78-2.29, RE: OR 1.27; 95\% CI 0.70-2.30, MH: OR 1.57; 95\% CI 0.89-2.75) (Figure 3b).

\section{Discussion}

In the present study we investigated the relationship between beta-blockers and HRQOL in patients with peripheral arterial disease and COPD. Our findings indicate that beta-blocker therapy does not impair HRQOL in this patient population.

These data are similar to a recent review and meta-analysis in patients with chronic heart failure, which demonstrated that beta-blocker therapy did not impair HRQOL. ${ }^{22}$ We extend these findings by demonstrating a similar relationship in COPD patients. The results of our study are also consistent with those reported by Mascarenhas and colleagues ${ }^{23}$ who in a cohort of patients with heart failure and COPD, found a low withdrawal rate of beta-blockers because of adverse effects among those who used these drugs.

Although clinicians are reluctant to prescribe beta-blockers to COPD patients for fear of provoking bronchospasm and exacerbating lung dysfunction, there is compelling evidence to indicate that the benefits (related to cardiovascular morbidity and mortality) are likely to outweigh the potential risk of adverse events in patients with COPD, especially when beta1-selective beta-blockers are used. ${ }^{11-13,24}$ Previous studies suggest that beta1-selective beta-blockers can be given safely to patients with COPD and do not worsen pulmonary function at least in the short-term when used cautiously. ${ }^{5-10}$ We have also observed previously that intensified doses of beta-blockers were superior to low-dose therapy in reducing mortality in patients with COPD, which suggests that although it is reasonable to initiate beta-blockers at a low dose, if possible, the dose should be titrated upwards judiciously and slowly to the therapeutic doses in these patients. ${ }^{13}$

Besides survival and adverse effect, it is also important to study the impact of medical treatment on patients' perspective of their health status. To date, HRQOL is often used as a secondary endpoint. However, as the focus of COPD management is to improve HRQOL, it is important that HRQOL is not adversely affected by medical therapy that potentially prolongs survival, eg, by the treatment with beta-blockers. Moreover, knowledge of the patients' perception of the effect of therapy is essential for the physicians' treatment decisions. Importantly, the results of our study indicate that beta-blocker therapy does not impair patients' health status and could be used in patients with cardiovascular disease and COPD.

The study has some limitations. First, our study was not a randomized controlled trial. As such, although adjustments were made for known covariates, there is the possibility of confounding by unmeasured variables. In addition, beta-blockers were not randomly assigned and therefore subject to confounding by indication. However, propensity analysis was performed to adjust as much as possible for this type of bias. ${ }^{25} \mathrm{We}$ did 
A

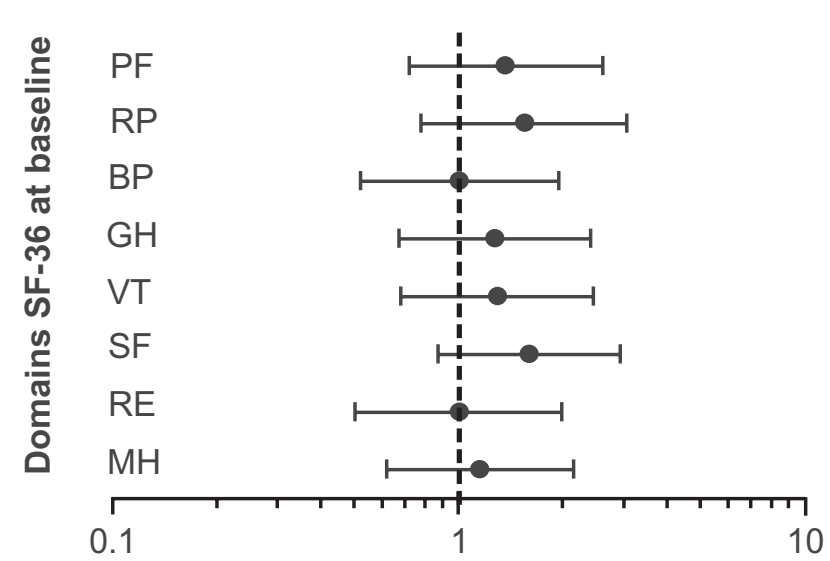

Adjusted OR (95\% Cl)

B

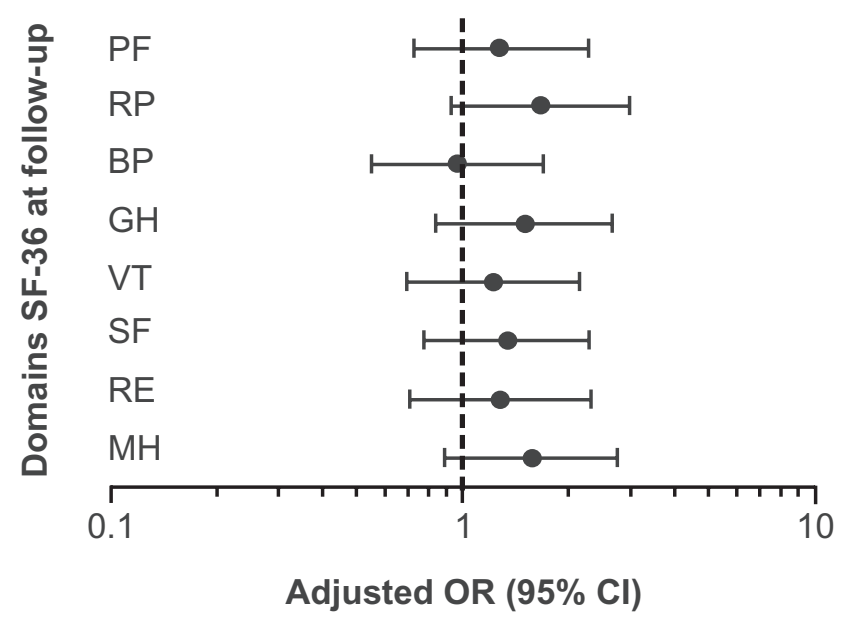

Figure 3 The association between beta-blocker therapy and health-related quality of life (HRQOL). A) The adjusted association between beta-blocker therapy at baseline and HRQOL; B) The adjusted association between beta-blocker therapy at follow-up and HRQOL. Adjusted for age, gender, diabetes mellitus, hypertension, hypercholesterolemia, renal dysfunction, current smoking, obesity, type of surgery, previous ischemic heart disease, heart failure, cerebrovascular event or transient ischemic attack, statins, aspirin, corticosteroids, bronchodilators, year of surgery, number of follow-up years (for Figure 2a) and propensity score.

Abbreviations: PF, physical functioning; RP, role physical; BP, bodily pain; $\mathrm{GH}$, general health; VT, vitality; SF, social functioning; RE, role emotional; $M H$, mental health; $O R$, odds ratio; $\mathrm{Cl}$, confidence interval.

not have accurate information on the duration of beta-blocker exposure and non exposure. A more detailed analysis of the relationship between the duration of beta-blocker exposure (or non-exposure) at follow-up and HRQOL was therefore not possible (eg, a time-dependent covariate analysis). For these and other reasons, a randomized controlled trial is needed to validate these early findings. Furthermore, during follow-up, a number of patients stopped using beta-blockers. It was reassuring that patients did not report worsening of their lung condition or respiratory symptoms for the discontinuation. Nevertheless, a more detailed assessment of long-term pulmonary on and off beta-blockers, using patient-based symptoms questionnaire and lung function testing, would be helpful to better understand why certain patients with COPD discontinue beta-blocker therapy during follow-up.

In sum, although beta-blockers are often indicated in patients with cardiovascular disease, clinicians are reluctant to prescribe these drugs to patients with co-existing COPD for fear of inducing bronchospasm and worsening their health status. The findings of the present study suggest that general health status is not materially affected by these drugs. In view of their potential life-preserving effects in patients with cardiovascular disease, these results suggest that beta-blockers can in most circumstances be judiciously administered to patients with COPD without impairing their HRQOL.

\section{Acknowledgments}

YRBM van Gestel and SE Hoeks are supported by an unrestricted research grant from "Lijf \& Leven" Foundation, Rotterdam, The Netherlands.

\section{Conflict of interest}

The authors disclose no conflicts of interest.

\section{References}

1. Sin DD, Anthonisen NR, Soriano JB, Agusti AG. Mortality in COPD: Role of comorbidities. Eur Respir J. 2006;6:1245-1257.

2. Mangano DT, Layug EL, Wallace A, Tateo I. Effect of atenolol on mortality and cardiovascular morbidity after noncardiac surgery. Multicenter Study of Perioperative Ischemia Research Group. N Engl J Med. 1996;23:1713-1720.

3. Poldermans D, Boersma E, Bax JJ, et al. The effect of bisoprolol on perioperative mortality and myocardial infarction in high-risk patients undergoing vascular surgery. Dutch Echocardiographic Cardiac Risk Evaluation Applying Stress Echocardiography Study Group. N Engl J Med. 1999;24:1789-1794.

4. Egred M, Shaw S, Mohammad B, Waitt P, Rodrigues E. Under-use of beta-blockers in patients with ischaemic heart disease and concomitant chronic obstructive pulmonary disease. QJM. 2005;7:493-497.

5. Ashrafian H, Violaris AG. Beta-blocker therapy of cardiovascular diseases in patients with bronchial asthma or COPD: The pro viewpoint. Prim Care Respir J. 2005;5:236-241.

6. Camsari A, Arikan S, Avan C, et al. Metoprolol, a beta-1 selective blocker, can be used safely in coronary artery disease patients with chronic obstructive pulmonary disease. Heart Vessels. 2003;4:188-192.

7. Kieran SM, Cahill RA, Browne I, Sheehan SJ, Mehigan D, Barry MC. The effect of perioperative beta-blockade on the pulmonary function of patients undergoing major arterial surgery. Eur J Vasc Endovasc Surg. 2006;3:305-308.

8. Salpeter S, Ormiston T, Salpeter E. Cardioselective beta-blockers for chronic obstructive pulmonary disease. Cochrane Database Syst Rev. 2005;4:CD003566.

9. Salpeter SR, Ormiston TM, Salpeter EE. Cardioselective beta-blockers in patients with reactive airway disease: a meta-analysis. Ann Intern Med. 2002;9:715-725. 
10. Sirak TE, Jelic S, Le Jemtel TH. Therapeutic update: non-selective beta- and alpha-adrenergic blockade in patients with coexistent chronic obstructive pulmonary disease and chronic heart failure. $\mathrm{J} \mathrm{Am} \mathrm{Coll}$ Cardiol. 2004;3:497-502.

11. Chen J, Radford MJ, Wang Y, Marciniak TA, Krumholz HM. Effectiveness of beta-blocker therapy after acute myocardial infarction in elderly patients with chronic obstructive pulmonary disease or asthma. J Am Coll Cardiol. 2001;7:1950-1956.

12. Gottlieb SS, McCarter RJ, Vogel RA. Effect of beta-blockade on mortality among high-risk and low-risk patients after myocardial infarction. N Engl J Med. 1998;8:489-497.

13. van Gestel YR, Hoeks SE, Sin DD, et al. Impact of cardioselective beta-blockers on mortality in patients with chronic obstructive pulmonary disease and atherosclerosis. Am J Respir Crit Care Med. 2008;7:695-700

14. Rabe KF, Hurd S, Anzueto A, et al. Global strategy for the diagnosis, management, and prevention of chronic obstructive pulmonary disease: GOLD executive summary. Am J Respir Crit Care Med 2007;6:532-555.

15. Ware JE Jr, Sherbourne CD. The MOS 36-item short-form health survey (SF-36). I. Conceptual framework and item selection. Med Care. 1992;6:473-483.

16. Aaronson NK, Muller M, Cohen PD, et al. Translation, validation, and norming of the Dutch language version of the SF-36 Health Survey in community and chronic disease populations. $J$ Clin Epidemiol. 1998;11:1055-1068

17. Harper R, Brazier JE, Waterhouse JC, Walters SJ, Jones NM, Howard P. Comparison of outcome measures for patients with chronic obstructive pulmonary disease (COPD) in an outpatient setting. Thorax. 1997;10:879-887.

18. Mahler DA, Mackowiak JI. Evaluation of the short-form 36-item questionnaire to measure health-related quality of life in patients with COPD. Chest. 1995;6:1585-1589.
19. Desikan R, Mason HL, Rupp MT, Skehan M. Health-related quality of life and healthcare resource utilization by COPD patients: a comparison of three instruments. Qual Life Res. 2002;8:739-751.

20. Rumsfeld JS, Magid DJ, Plomondon ME, et al. History of depression, angina, and quality of life after acute coronary syndromes. Am Heart J. 2003;3:493-499.

21. Spertus JA, Jones P, McDonell M, Fan V, Fihn SD. Health status predicts long-term outcome in outpatients with coronary disease. Circulation. 2002;1:43-49.

22. Dobre D, van Jaarsveld CH, deJongste MJ, Haaijer Ruskamp FM, Ranchor AV. The effect of beta-blocker therapy on quality of life in heart failure patients: a systematic review and meta-analysis. Pharmacoepidemiol Drug Saf. 2007;2:152-159.

23. Mascarenhas J, Lourenco P, Lopes R, Azevedo A, Bettencourt P. Chronic obstructive pulmonary disease in heart failure. Prevalence, therapeutic and prognostic implications. Am Heart J. 2008;3:521-525.

24. Antman EM, Hand M, Armstrong PW, et al. 2007 Focused Update of the ACC/AHA 2004 Guidelines for the Management of Patients With ST-Elevation Myocardial Infarction: a report of the American College of Cardiology/American Heart Association Task Force on Practice Guidelines: developed in collaboration With the Canadian Cardiovascular Society endorsed by the American Academy of Family Physicians: 2007 Writing Group to Review New Evidence and Update the ACC/AHA 2004 Guidelines for the Management of Patients With ST-Elevation Myocardial Infarction, Writing on Behalf of the 2004 Writing Committee. Circulation. 2008;2: 296-329.

25. D'Agostino RB Jr. Propensity score methods for bias reduction in the comparison of a treatment to a non-randomized control group. Stat Med. 1998;19:2265-2281.
International Journal of COPD

\section{Publish your work in this journal}

The International Journal of COPD is an international, peer-reviewed journal of therapeutics and pharmacology focusing on concise rapid reporting of clinical studies and reviews in COPD. Special focus is given to the pathophysiological processes underlying the disease, intervention programs, patient focused education, and self management protocols

\section{Dovepress}

This journal is indexed on PubMed Central, MedLine and CAS. The manuscript management system is completely online and includes a very quick and fair peer-review system, which is all easy to use. Visit http://www.dovepress.com/testimonials.php to read real quotes from published authors. 